\title{
A IMPORTÂNCIA DA CURVA ABC NA GESTÃO DO ESTOQUE
}

\author{
Edelmar Franklin de Lima Calheiros ${ }^{1}$ \\ Arandi Maciel Campelo ${ }^{2}$
}

\section{RESUMO}

O presente trabalho visa colaborar com estudos na área quanto à observação da importância da curva $\mathrm{ABC}$ para a boa gestão de estoque nas empresas, pois um bom gerenciamento de estoque significa que a empresa garante seus lucros e pode investir onde realmente for mais necessário. A curva $\mathrm{ABC}$ é uma matriz de divisão de itens que auxilia na tomada de decisões de reposição de estoque. Um questionário foi aplicado a alguns colaboradores de uma empresa em Jaboatão dos Guararapes. Foi possível concluir que ela mostra os itens a serem repostos, tornando o trabalho mais fácil e eficaz para o gestor.

Palavras-chave: Curva ABC. Gestão de estoque. Trabalho eficaz.

Data de submissão: $28 / 03 / 2020$

Data de aprovação: 19/04/2020

\section{INTRODUÇÃO}

O tema escolhido para apresentação deste artigo deve-se ao interesse sobre o assunto e por trabalhar na área de gestão de estoque. Sabendo da importância de uma boa gestão neste setor, fica evidenciado a vontade e a satisfação de escrever sobre esta temática.

A boa execução em um gerenciamento de estoque significa que a empresa tem potencial para garantir seus lucros e poder investir onde realmente for mais necessário, evitando perdas financeiras e materiais, como o investimento em um estoque onde o produto é mal armazenado ou alocado em um lugar onde não era para ser, desencadeando perda do produto.

Ao executar os métodos corretos para minimizar perdas, o desperdício evitado poderá gerar mais receitas para a organização, mostrando que teve um bom gerenciamento com investimentos em outras áreas ou setores.

Sabendo desta realidade, fica claro que toda organização ou qualquer área que trabalhe com esse tipo de segmento tem que dar uma atenção especial ao tema. Isso será de grande

1 Discente do curso de Administração da FMGR. E-mail: edelmar.calheiros@hotmail.com

2 Professor, orientador e diretor acadêmico da FMGR. E-mail: arandi.campelo@globo.com 
importância para uma boa gestão de modo a que sirva de base para melhorias no gerenciamento de estoque.

\section{REFERENCIAL TEÓRICO}

Em administração de estoque a curva $\mathrm{ABC}$ auxilia para a compra do necessário, evitando as perdas de recursos ou investimentos indesejados e otimizando o trabalho. É uma ferramenta que auxilia na hora da compra, uma vez que um estoque em excesso pode fazer com que o dinheiro fique congelado, deixando de investir em outras áreas. Entretanto, o baixo estoque pode parar a produção por falta de recursos ou perder uma venda por falta do produto.

A curva $\mathrm{ABC}$ é uma matriz de divisão de itens que auxilia na tomada de decisões de reposição de estoque, sendo caracterizada da seguinte forma: itens A são aqueles com maior giro, itens B são os de giro médio, e itens C são os que possuem baixo giro. Esta classificação facilita a divisão do estoque e nos dá um norte na hora de avaliar a reposição.

Ficar com uma peça ou produto muito tempo no estoque significa que a compra está sendo realizada de forma errada. Isso faz com que o item ocupe espaço e congele o capital, prejudicando o resultado final. Tal fato pode mostrar que a demanda está maior que a oferta.

Um bom controle é capaz de garantir uma venda quando o concorrente não tem o produto. Um controle eficiente pode garantir a venda de forma mais saudável, atendendo de forma rápida e deixando o cliente satisfeito. Conforme cita Slack et al (2009), o estoque ocorre porque não há harmonia entre fornecimento e demanda, representando recursos em transformação. Para gerir o estoque devem-se considerar aspectos da gestão da demanda, administração de transportes e o espaço físico disponível para o armazenamento de materiais.

Podemos definir essa matriz da seguinte forma: A para os itens que giram em média três meses, B para os itens com demanda média de três a seis meses, e C para itens com giro de seis meses em diante. Isso ajudará na análise, auxiliando o comprador ou o responsável pela compra a solicitar somente o que for necessário.

Devemos levar em consideração o estoque mínimo ou estoque de segurança que é uma quantidade mínima que devemos deixar disponível por eventuais atrasos de transportadoras ou demora de atendimento do fornecedor, garantindo que não haverá falta. Desta forma, haverá uma margem de erro para possíveis imprevistos, otimizando os problemas que são gerados pela falta de estoque mínimo. Assim, a criação do estoque mínimo é importante para que não haja a falta do produto. 
Se a demanda é estável, fica fácil calcular. Se for sazonal, devemos comparar com anos ou períodos anteriores para se ter uma noção do que realmente é necessário. Segundo Botter \& Fortuin (2000), apesar do vasto embasamento teórico para a gestão de estoques de itens em geral, a literatura sobre a gestão de peças de reposição tende a ser mais escassa. Assim sendo, para se calcular a demanda, tem que ter o conhecimento da venda e de quanto tempo este produto leva para estar em nossas mãos novamente. Exemplo: existe uma venda diária de 5 peças e o tempo de espera para que ela esteja novamente para venda é de 6 dias. Então, calcula-se da seguinte forma o estoque de segurança: $5 \times 6=30$. Portanto, a quantidade mínima será de 30 peças de segurança de estoque para fazer um novo pedido.

O estoque deve ser classificado da seguinte maneira:

a) Estoque em trânsito - são os produtos que foram solicitados ao fornecedor e foram faturados;

b) Estoque regular - é a capacidade do estoque com peças cíclicas, que repõe periodicamente;

c) Estoque de segurança - é o estoque adicional para eventuais incertezas de fornecimentos e atrasos de transportes, entre outros;

d) Estoque de obsoleto - são os itens que não têm giro, seja por má compra, planejamento errado ou mudança de mercado.

Tendo a compreensão dessa matriz, de como calcular sua demanda e dividi-las, facilitará o trabalho, minimizando a ocorrência de excessos e possíveis faltas. É de suma importância que a empresa tenha a mercadoria em estoque ao efetuar a venda, pois agilizará a necessidade do cliente, evitando que ele vá para a concorrência. Neste caso, além de gerar satisfação para o cliente, o vendedor também se sente satisfeito com o sucesso do seu trabalho. O estoque tem que estar preparado para a demanda específica de cada seguimento.

\section{GESTÃO DE ESTOQUE}

$\mathrm{Na}$ gestão de estoque devemos ser o mais eficiente possível, avaliando de forma sucinta as ferramentas de auxílio de tomada de decisão, a fim de obter o máximo de eficiência e lucro necessário, tendo o equilíbrio do estoque entre oferta e demanda.

De acordo com Wanke (2003), a gestão de estoque engloba todo um processo de decisões que envolvem tempo e espaço, verificando a demanda de produtos de forma que sejam atingidos os objetivos de custos e serviços. 
Há variados custos em uma gestão de estoque: de armazenagem, de aquisição, pela falta e custos de pedidos. Deve haver bom senso na hora de avaliar todos estes pontos. Uma boa gestão passa pelo equilíbrio de todas essas variantes, com o gestor tendo que ter um feeling muito importante na avaliação. Segundo Pozo (2010), é praticamente impossível prever com exatidão a demanda futura, sendo necessário manter certo nível de estoque para assegurar a disponibilidade de produtos.

No gerenciamento do estoque o responsável tem que se ater a três pontos: quanto pedir, como pedir, e como ajustar o sistema para quais dias serão colocados os pedidos. Desta forma, com os processos definidos, fica bem mais fácil a organização do setor.

Conforme a linha de raciocínio de Bowersox \& Colss:

Controle de estoques é um procedimento rotineiro necessário ao cumprimento de uma política de estoques. O controle abrange as quantidades disponíveis numa determinada localização e acompanha suas variações ao longo do tempo. Essas funções podem ser desempenhadas manualmente ou por computador. As principais diferenças são a velocidade a precisão e o custo. (BOWERSOX; COLSS, 2010, p. 255).

Dentro do estoque, a armazenagem deve ser de forma simples e com lugares específicos, tendo para cada produto uma locação para que não se perca. Se possível cada item deve estar relacionado no sistema, facilitando assim para todos os envolvidos no processo.

$\mathrm{Na}$ armazenagem podemos definir locação por endereço ou código específico: rua, letra ou a que seja melhor para cada segmento, mas nunca deixar de definir um local es pecífico para que todos tenham acesso ao local de armazenagem. Assim, fica muito mais fácil achar cada item dentro de um estoque. Sempre que for realocar ou tirar algum item do almoxarifado deve-se utilizar o sistema descrito por Carvalho \& Macedo:

Devem ser implantados sistemas de FIFO (First In First Out) ou FEFO (First Expired First Out), "Primeiro que Entra Primeiro que Sai" ou "Primeiro que Vence Primeiro que Sai". O controle de entrada e saída deve ser feito por meio de programas de informação validados, que permitam a emissão de relatórios periódicos. (CARVALHO; MACEDO, 2010, p. 59).

A falta de sistemas que não ajudam nessa automação ou a ausência de pessoas capacitadas coloca todo um resultado e esforço de gestão a perder. Pessoas bem treinadas e ferramentas apropriadas facilitam na organização e na qualidade de cada estoque. Ao se deparar com um almoxarifado organizado, não se imagina a quantidade de processos que existem por trás de toda essa organização. 
Mesmo um estoque adequado tem que ser sempre monitorado com programas de melhorias contínuas para que erros atuais não sejam repetidos no futuro e assim seja eficiente e eficaz. $\mathrm{Na}$ organização de estoque existe a regra dos 5 Ps: pessoas, processos, procedimentos, processamentos e prateleiras.

a) Pessoas - devem ser contratadas equipes competentes e motivadas para a boa saúde da empresa;

b) Processos - devem ser mapeados os procedimentos com medição de indicadores de desempenho e processos de melhoria contínua;

c) Procedimentos - trata-se da fiscalização dos processos, conferindo se o físico é igual ao virtual. Se possível deve-se fazer o balanço periódico para garantir o andamento dos processos;

d) Processamentos - todas as transações que envolvem o estoque devem ocorrer da mesma forma que no caixa de um banco. Devem sempre ser processadas (registradas) as saídas ou entradas de cada item.

e) Prateleiras - deve-se observar a organização de estocagem, garantindo que serão colocados de forma adequada, que não haja prateleiras amassadas e o que está estocado não esteja passando do tamanho da locação.

Assim sendo, um conjunto de fatores são necessários para uma boa gestão, garantindo a fluidez dos processos e melhorias do setor responsável.

\section{CONTROLE DE ESTOQUE FÍSICO E CONTÁBIL}

O controle físico e financeiro tem por finalidade acompanhar o que existe de fato com a quantidade no sistema, seja ele para vendas ou consumo de produtos existentes em uma empresa.

Controlar as entradas e saídas de insumos ou produtos é muito importante para se ter o domínio do estoque. A cada momento em que chegar materiais eles devem ser conferidos antes de serem inseridos no sistema. Se encontrar alguma divergência devemos fazer a notificação e só depois do caso resolvido dar prosseguimento ao serviço. Com relação às saídas sempre devemos fazer o registro na ficha ou no programa de gerenciamento, evitando divergências.

Grande parte das empresas ou microempresas não faz o registro no sistema de forma eficaz, gerando divergências entre o que está registrado e o real. Essa falta de controle prejudica o gerenciamento. Este registro é fundamental, pois na hora de fazer os pedidos de 
reposição sabe-se exatamente o que e o quanto se deve comprar, evitando problemas de falta ou excesso de produtos. Isso pode causar um efeito dominó, prejudicando toda a empresa. Um mau atendimento, a perda de uma venda ou a baixa no faturamento podem ser consequências da falta de controle em que produtos ou insumos estejam divergentes no estoque.

Muitas empresas dimensionam o estoque por necessidade, incômodo ou conveniência. É preciso manter a regra do estoque mínimo para não comprometer as finanças. Um exemplo é o excesso de um item que representa um capital parado e que poderia ser investido em outro local. Há também o risco de vencimento do produto e ainda o custo do espaço ocupado. Em contrapartida, a falta de determinado item pode ocasionar a perda da venda ou a parada da produção, gerando custos por conta da ociosidade. Conforme cita Palmisano (2004):

Quando a empresa mantém estoques que não são necessários, ocorre um desaproveitamento de estoque, o que vai significar uma perda de espaço físico, assim como perdas de investimento. Quando existe a consciência que os estoques geram desperdício e quando se identificam as razões que indicam a necessidade de estoques, o propósito é usá-las de forma eficiente". (PALMISANO et al, 2004, p. 51).

Depois de tudo conferido e verificado, a atenção é muito importante na hora da entrada. Deve-se ter o cuidado para não lançar no sistema algo a mais ou a menos. Isso colocaria todo o trabalho a perder, acarretando divergências que prejudicariam a operação e também a parte financeira da empresa.

Para garantir a solidez do estoque é inerente a conferência periódica para detectar possíveis falhas e divergências. O inventário é essencial para todo administrador de estoque. $\mathrm{O}$ controle de pessoas que acessam o almoxarifado tem que ser rígido. Funcionários não autorizados não podem circular nestas áreas, evitando possíveis furtos. Câmeras de monitoramento devem auxiliar no trabalho de segurança.

Em relação aos preços eles devem ser ajustados de acordo com os valores atuais, principalmente para quem trabalha com exportação, pois fica dependente da variação do dólar, ou pode fazer o custo médio, não perdendo assim o poder de competitividade. O valor geral do estoque é formado pela soma de todos os custos individuais de cada produto.

O gestor tem que estar atento para saber a hora certa de lançar as promoções. Geralmente tira-se proveito dos excessos para liberar espaço e fazer com que haja o giro de estoque. O trabalho de marketing é importante para auxiliar nesse caso. 
No controle financeiro de estoque devemos observar alguns pontos: registrar custo unitário e custo das mercadorias vendidas, confirmar se o estoque está igual ao físico, verificar o fluxo de caixa e ver se bate o valor vendido com estoque. Desta forma, temos um controle total e uma boa gestão.

\section{METODOLOGIA}

O presente trabalho tem como foco gerir o estoque de forma eficiente em uma empresa, tirar proveito da boa gestão e sugerir melhorias, propondo um aprofundamento na área de trabalho em gestão de estoque.

A pesquisa, de caráter investigativo e exploratório, foi realizada em uma empresa da cidade de Jaboatão dos Guararapes, em Pernambuco. Foi aplicado um questionário e coletadas amostras de cinco participantes em um universo de 12 pessoas.

\section{DESENVOLVIMENTO DA PESQUISA DE CAMPO}

O questionário foi elaborado em três etapas. A primeira, com perguntas sobre o sexo, faixa etária, último curso que concluiu, tempo em que está na empresa e o cargo atual; a segunda, com resposta sim ou não, sobre como é a relação pessoal entre o funcionário e a empresa; e a terceira e última com 10 perguntas objetivas a depender do grau de concordância do entrevistado. Em um universo de 12 funcionários foram entrevistadas 05 pessoas, totalizando assim um percentual de $41,67 \%$.

A maioria dos entrevistados que respondeu ao questionário mostrou o quão importante é trabalhar com pessoas experientes na área. Para que sejam compartilhados os conhecimentos e assim trazer melhorias para a empresa, a teoria e a prática devem acontecer de forma paralela.

\section{CURVA ABC}

A curva $A B C$ é basicamente a classificação por ordem de itens de alto giro (A), itens de giro médio (B), e itens de baixo giro (C). Desta forma fica mais fácil na hora de fazer os pedidos de compras para reposição do estoque, evitando que seja pedido um item que não sai e nem deixando de repor um item de alto giro, o que poderia causar falta no estoque, perda da venda ou a parada da produção.

Boa parte dos entrevistados tinha conhecimento sobre o que é a curva $\mathrm{ABC}$, mostrando assim a importância dessa ferramenta em uma gestão de estoque. Fica evidente o quão importante é ser conhecedor deste método. 


\section{CURVA XYZ}

A curva XYZ demonstra o impacto do capital investido no estoque, de forma que podemos controlar para rentabilizar ao máximo o investimento.

De modo geral, o controle do estoque fica mais criterioso e podemos ter uma noção melhor do que é realmente necessário e o que mais está impactando financeiramente o estoque, seja ele no varejo, atacado ou em produção para reposição de estoque.

Buscar o conhecimento em boa gestão mostra o benefício que traz, não só para o lado pessoal, mas para o lado profissional. Boa parte dos entrevistados mostrou conhecimento sobre a curva XYZ, evidenciando o comprometimento da empresa com o treinamento da equipe, trazendo benefícios para si como profissionais qualificados.

\section{ESTOCAGEM E ORGANIZAÇÃO}

Vimos na introdução a importância de se ter uma boa organização e quão grandes são os benefícios de se ter uma boa estocagem. Sobre o questionário, não fica dúvida sobre a relevância deste tema. Todos foram unânimes na resposta, mostrando que é benéfico não só para a empresa.

\section{CONSIDERAÇÕES FINAIS}

A curva $\mathrm{ABC}$ é uma matriz de análise que nos auxilia na tomada de decisão na hora do pedido de reposição de estoque. Ela nos mostra os itens a serem repostos, tornando o trabalho mais fácil e eficaz para o gestor. A boa gestão em uma organização facilita o trabalho de todos e economiza tempo e recursos.

A empresa analisada em Jaboatão dos Guararapes-PE tem uma gestão que visa à redução de custos. Foi verificado todo o processo desse segmento. As atividades são mais eficientes na tomada de decisão para evitar desperdícios e rentabilizar resultados que possam proporcionar lucro para a empresa. O responsável pelo gerenciamento deve observar três pontos: quanto pedir, como pedir e como ajustar o sistema para fazer a leitura de forma adequada.

$\mathrm{Na}$ armazenagem foram verificadas falhas nas locações com alguns itens alocados de forma inadequada. Foi sugerida a implantação da regra dos 5 Ps. Assim sendo, um conjunto de fatores são necessários para uma boa gestão, garantindo a fluidez dos processos e a melhoria do setor responsável. 
Em um universo de 12 pessoas 5 foram pesquisadas. Desta forma fica evidenciada a importância de se investir em pessoas e processos. Conforme o questionário, foi mencionado a importância de trabalhar com pessoas experientes. É importante, de acordo com a pesquisa, rastrear os trabalhos efetuados para identificar possíveis erros na busca da melhoria contínua.

Tendo o conhecimento de tudo que foi mencionado neste artigo, fica evidenciado a importância deste trabalho. O questionário aplicado mostra a importância da experiência na área em que atuam. Isso justifica a importância dos investimentos em conhecimento no trabalho dos envolvidos.

Como sugestão, os pesquisadores podem aprofundar-se neste assunto, ajudando a contribuir na otimização dos trabalhos e economizando não só tempo, mas dinheiro, permitindo que todos os interessados possam ter acesso a esta pesquisa.

\section{REFERÊNCIAS}

BOTTER, R.; FORTUIN, L. Stocking strategy for service parts: a case study. International Journal of Operations \& Production Management, Bingley, UK, v. 20, n. 6, p. 656-674, 2000.

BOWERSOX, D. J.; CLOSS, D. J. Logística Empresarial. São Paulo: Atlas, 2010.

CARVAlHO, S.; MACEDO, S. Logística Farmacêutica Comentada. São Paulo: Medfarma, 2010.

PALMISANO, A. et al. Gestão da qualidade - tópicos avançados. Cengage Learning Editores, 2004.

POZO, H. Administração de Recursos Materiais e Patrimoniais. 6. ed. São Paulo: Atlas, 2010 .

SLACK, Nigel; CHAMBERS, Stuart; JOHNSTON, Robert. Administração da produção. 3. ed. São Paulo: Atlas, 2009.

WANKE, P. Gestão de estoques na cadeia de suprimento. São Paulo: Atlas, 2003. 


\section{APÊNDICE A - Questionário da pesquisa}

\section{Informações gerais}

Favor marcar com um $\underline{\mathbf{X}}$ somente em uma única resposta que melhor se apresente para você.

1. Sexo:

Masculino

Feminino

2. Faixa de idade:

Até 25 anos

$\square$ De 25 a 35 anos

$\square$ De 35 a 45 anos

$\square$ De 45 a 60 anos Acima de 60 anos

3. Último curso que você concluiu:

$\square$ Doutorado

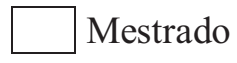

$\square$ Especialização

$\square 3^{\circ}$ grau

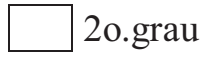

$\square$ Outro

4. Tempo em que você está na empresa:

1 ano ou menos

$\square$ De 1 a 3 anos

$\square$ De 3 a 5 anos

De 5 a 10 anos

Mais de 10 anos

5. Seu cargo na empresa:

$\square$ Direção

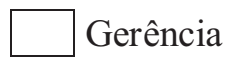

$\square$ Coordenação/liderança

Estoquista

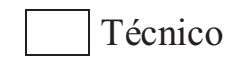

6. Você é formalmente incentivado pela empresa a compartilhar o que você sabe?

Sim

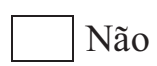

7. Sua empresa dispõe de instrumentos ou métodos formais para você compartilhar conhecimento?

$\square \operatorname{Sim}$

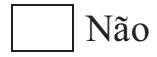

8. Você participa de alguma atividade de gerenciamento de estoque (Planejamento do gerenciamento, Identificação, Monitoramento de melhorias, Comunicação)?

$\operatorname{Sim}$ 
Favor responder ao questionário considerando sua percepção ou opinião quanto às afirmativas, circulando o número que corresponde ao seu grau de concordância.

\begin{tabular}{|c|c|c|c|c|c|c|}
\hline & 1 - Discordo totalmente 2 - Discordo parcialmente 3 - Indifere & & & & & \\
\hline & 4 - Concordo Parcialmente 5 - Concordo totalmente & & & & & \\
\hline 01 & $\begin{array}{l}\text { Considero a vivência com profissionais experientes no gerenciamento de estoque algo } \\
\text { extremamente valioso. }\end{array}$ & 1 & 2 & 3 & 4 & 5 \\
\hline 02 & Recebo ajuda de pessoas com o mesmo interesse em organização de estoque. & 1 & 2 & 3 & 4 & 5 \\
\hline 03 & $\begin{array}{l}\text { Identifico os erros ocorridos e faço as notificações no livro de ocorrências ou comunico } \\
\text { ao responsável para a notificação. }\end{array}$ & 1 & 2 & 3 & 4 & 5 \\
\hline 04 & $\begin{array}{l}\text { Para identificar possíveis erros, todo trabalho efetuado é identificado, assim como o } \\
\text { colaborador que fez tal serviço. }\end{array}$ & 1 & 2 & 3 & 4 & 5 \\
\hline 05 & Tenho ciência dos significados da curva ABC e da curva XYZ. & 1 & 2 & 3 & 4 & 5 \\
\hline 06 & Sei do processo de estocagem e do significado das siglas PEPS / FIFO. & 1 & 2 & 3 & 4 & 5 \\
\hline 07 & $\begin{array}{l}\text { Tenho conhecimento sobre o sistema utilizado na empresa e habilidade para manuseá- } \\
\text { lo. }\end{array}$ & 1 & 2 & 3 & 4 & 5 \\
\hline 08 & Existem relatórios gerenciais que podem me auxiliar no meu trabalho diário. & 1 & 2 & 3 & 4 & 5 \\
\hline 09 & Participo de reuniões, quando necessário, para explanar erros e sugerir melhorias. & 1 & 2 & 3 & 4 & 5 \\
\hline 10 & $\begin{array}{l}\text { Considero-me um funcionário apto e com conhecimento na minha área de atuação e } \\
\text { que esses conhecimentos são transmitidos para a empresa como benefício. }\end{array}$ & 1 & 2 & 3 & 4 & 5 \\
\hline
\end{tabular}

Fonte: os autores 


\section{ANEXO A - Curva ABC e curva XYZ}

Importância do item (valor consumido)

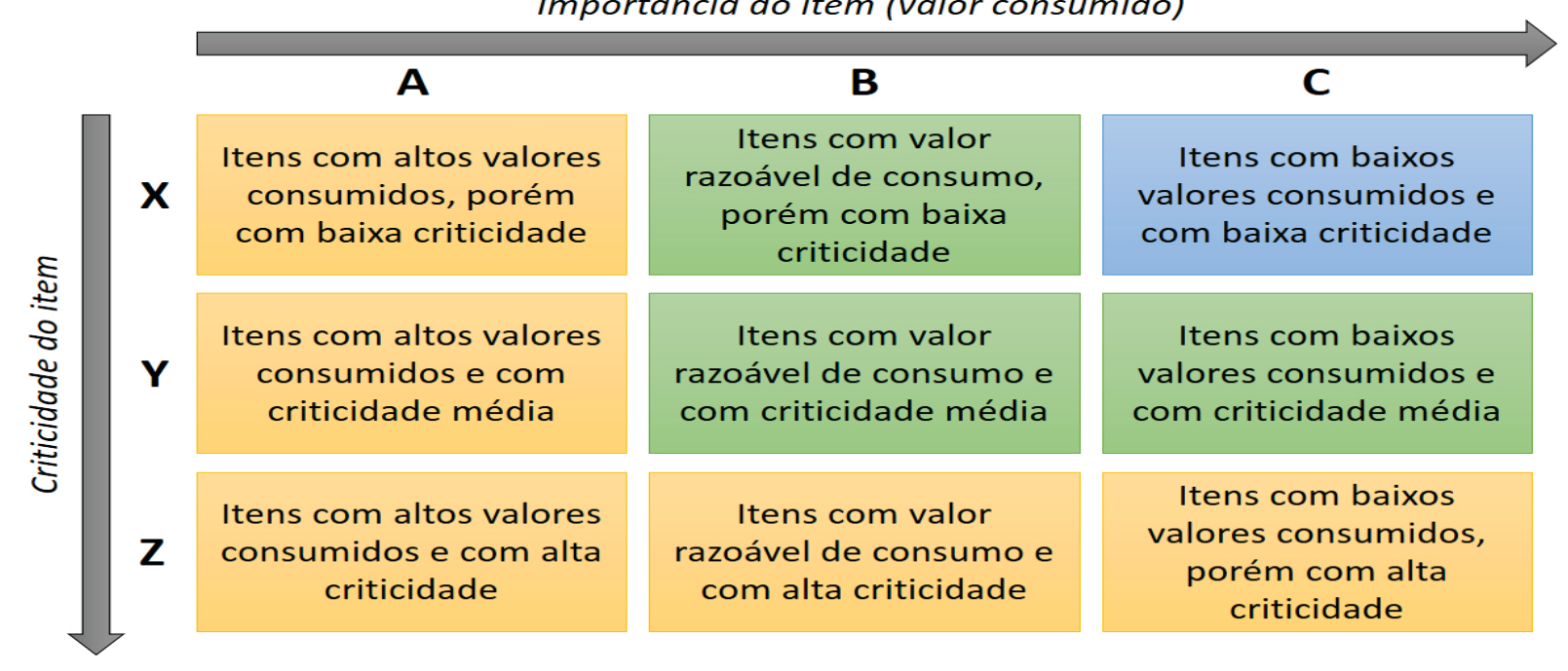

Fonte: Lima (2016). 